Published in Endeavour 40 (2016) 131-134

http://dx.doi.org/10.1016/i.endeavour.2016.03.001

(c) Elsevier Ltd.

\title{
The Missing Skull - Professor Lundborg and the Mismeasure of Grandma
}

\author{
Henrik Kylin \\ Department of Thematic Studies - Environmental Change \\ Linköping University \\ SE-581 83 Linköping \\ Sweden \\ Research Unit: Environmental Sciences and Development \\ North-West University \\ P. Bag X6001 \\ Potchefstroom 2520 \\ South Africa \\ E-mail: henrik.kylin@liu.se \\ Phone: (46)13282278
}

What is science? Or, more pertinently, what is good science? This question is central for all practitioners of science and one of the most important to convey to our students. For those of us working in interdisciplinary settings - my own department covers everything from humanities to political and natural science - the question becomes even more complicated when traditions from different disciplines collide. For me personally, whenever I think too highly of my own research and risk deviating into bad scientific practices, I think of my paternal grandmother, Elsa. Although long dead, she brings me back into the fold of good science - or so I hope - by urging me to take another turn at critically evaluating how I perform research and to keep my arrogance in check.

\section{Skull Collections and Collecting}

On $27^{\text {th }}$ January 1945 , Auschwitz was liberated. The $70^{\text {th }}$ anniversary of the liberation released a round of journalistic "discoveries" of the anatomical collections deposited in various Swedish institutions. During the past 40 years, such journalistic feats occur about once every decade; each time introducing a new generation to historical facts about bad research practices that flourished not long ago; each time triggering discussions about how Swedish scientists promoted eugenics sterilizing individuals of so-called "inferior" hereditary quality - and contributed to the development of craniometry - the measurement of skulls to determine an individual's "race" - and racial biology. ${ }^{1}$

Swedish $19^{\text {th }}$ century scientists Gustaf and Anders Retzius, "fathers of Swedish anatomical science", were prime movers of skull collecting and craniometry. Hence, the journalistic target this time was

\footnotetext{
${ }^{1}$ While I use the term "inferior" throughout, I recognize that the term is problematic and it does not reflect my own standpoint. However, the term was used widely by the proponents of racial biology, "racial hygiene", and eugenics and is used here to reflect the arguments of that particular debate. For wider a discussion see: Broberg, G., Roll-Hansen, N. (eds.) Eugenics and the welfare state: Sterilization policy in Denmark, Sweden, Norway, and Finland. East Lansing, MI: State University of Michigan Press; 2005.
} 
their skull collection at the Karolinska Institute - Sweden's leading medical research institute at which the Retziuses were active, and whose professors select the medical Nobel Prize laureates. The Retziuses, father and son, were held in such high esteem at the Karolinska Institute that a major building and a campus through-road were named after them when the institute moved to its present location in 1945.

Skull collecting throughout the $19^{\text {th }}$ and early $20^{\text {th }}$ centuries, was, to no small degree, motivated by an agenda to "objectively measure" differences between humans - to classify humans as individuals of higher or lower worth. ${ }^{2}$ The skull collections were expected to provide evidence to motivate existing social structures and prove the superiority of the "Nordic-Germanic race". ${ }^{3}$ Still, probably because of the thrill of exoticism, and the hope to show their inferiority, the skull collectors aggregated as many skulls of supposed "inferior" races as possible. Indigenous burial grounds and sacred places in Oceania, Africa, Asia, the Americas, and Northern Scandinavia were looted, sometimes by scientists, but also by "adventurers" who, in part, financed their travels by selling stolen skulls to anatomical collectors and those developing anatomical collections. ${ }^{4}$

In Sweden, there was particular interest in the Sami and Tornedalian indigenous communities of the North, but most of the skulls in the Swedish collections were of Swedish "majority race". ${ }^{5}$ According to Swedish $19^{\text {th }}$ century legislation, convicted villains, persons who committed suicide, and the inmates of mental institutions and workhouses at death did not own their own bodies, which, therefore, were used for dissections at medical training institutes. After dissection, the skulls of these individuals often ended up in collections as examples of humans with so-called "inferior" qualities. Exact statistics are difficult to come by, and the recent "rediscovery" of skull collections has demonstrated the paucity of good documentation in the past. ${ }^{6}$ However, among Swedish skulls that were not from archaeological digs, the overwhelming number of specimens in collections likely came from individuals that, for one reason or another, were regarded as socially or racially "inferior". In this respect, with so few so-called "superior" examples, one wonders how the skull measurements were expected to provide any relevant comparisons. However, we must consider that statistical methods in the $19^{\text {th }}$ century were neither as well developed, nor afforded as much importance as they are today, and since the primary outcome of the investigation (the superiority of the wealthy

\footnotetext{
${ }^{2}$ Ljungström, O. Oscariansk antropologi: Etnografi, förhistoria och rasforskning under sent 1800-tal. Stockholm, Sweden: Gidlunds; 2004. Svanberg, F. Människosamlarna - Anatomiska museer och rasvetenskap i Sverige ca 1850-1950. Stockholm, Sweden: The Swedish History Museum; 2014. Kyllingstad, J R. Measuring the Master Race: Physical Anthropology in Norway, 1890-1945. Cambridge, UK: Open Book Publishers; 2014

${ }^{3}$ Although the individual researchers may not have seen themselves as being racist, only collectors and systemisers of measurements, there was in the $19^{\text {th }}$ and early $20^{\text {th }}$ centuries a widespread notion of the superiority of the Nordic-Germanic race. Particularly in North America and North West Europe, in which the inhabitants considered themselves of mainly Germanic origin. The skull collections and craniometry transformed these notions of race into a scientific concept. For example, see: Kyllingstad, J R. Measuring the Master Race: Physical Anthropology in Norway, 1890-1945. Cambridge, UK: Open Book Publishers; 2014 ${ }^{4}$ Svanberg, F. Människosamlarna - Anatomiska museer och rasvetenskap i Sverige ca 1850-1950. Stockholm, Sweden: The Swedish History Museum; 2014.

${ }^{5}$ The Swedish majority, belonging to the "Nordic Race" was considered "superior" to the minority "races", Finns ("Eastern-Baltic"), Sami ("Lapps"), Romani ("Gypsies"), and Jews.

${ }^{6}$ The research questions asked during the collection period, with strong emphasis on skull indices, were such that limited documentation was systematized for each sample. For non-European samples, the documentation could consist of only country of origin and date of arrival at the institute. Svanberg, F. MänniskosamlarnaAnatomiska museer och rasvetenskap i Sverige ca 1850-1950. Stockholm, Sweden: The Swedish History Museum; 2014.
} 
white male) was already a given at that time, protagonists of craniometry were probably less concerned with any deficit in statistical significance.

If the story ended there, the collections themselves may not have triggered so much debate in the wake of the Auschwitz liberation anniversary. However, in 1922 the Swedish Parliament decided to finance the State Institute for Racial Biology in Uppsala. ${ }^{7}$ Officially, the initiative came from a social democratic member of parliament, but the motion was signed by parliamentarians from the whole political spectrum. Unofficially, Professor Dr. Herman Lundborg, an internationally acclaimed leading racial biologist, probably wrote the motion - and was rewarded by becoming the institute's first Director. ${ }^{7}$ Lundborg argued for the sterilization of supposedly "genetically inferior" individuals, moreover, his correspondence revealed that he was a Nazi sympathiser. ${ }^{8}$

\section{Grandmother Elsa}

Grandmother Elsa was one of the early female students at Uppsala University. Not the very first, but early enough for female students to still be an anomaly at the university. During Elsa's time in Uppsala, Herman Lundborg was in the ascendance as a world-leading racial biologist. Students at the University were easily accessible study material, and Lundborg took advantage of this situation by measuring Elsa up and down, and back and forth, before declaring her to be the "finest example of the pure Nordic Race" ${ }^{9}$ When Elsa later recalled these times to her grandson, she told me how Lundborg used her as a demonstration example during lectures so that her fellow students, notably all male, should really "imbibe the beauty of a female of the pure Nordic Race", and how she was photographed, both clad and nude, for the archives of the State Institute for Racial Biology.

Elsa died when I was nine, and at the time, I did not fully grasp the implications of her story. But aged 11 or 12, I found Lundborg's popular science pamphlet of the racial characters of the Swedish population on the family bookshelf. ${ }^{10}$ When I showed it to my father, he, to my distinct displeasure, was convinced that the female nude used to represent the "Nordic Race" was, in fact, Grandmother Elsa. (Figure 1).

In my early teens, contemplating my grandmother publicly displayed in the nude was of great embarrassment! Today, however, I primarily see a dreadful irony in Elsa's contacts with Lundborg. The reason: One would think that the good Professor, a self-affirmed proto-Nazi, should have realized that Elsa was not so Nordic. In fact, this so-called "finest example of the pure Nordic Race", Elsa Jacobowsky, was $100 \%$ Jewess! ${ }^{11}$ Obviously, to Lundborg, Elsa's cranial index and general posture were more important than her name and ancestry when he assigned her to one of his predefined racial groups.

We could end here: with a laugh at how former generations of scientists could perform bad science, and with the rather obvious conclusion that racial biology simply was Bad Science; a faulted

\footnotetext{
${ }^{7}$ Broberg, G. Ugglan 4: Statlig rasforskning. En historik över Rasbiologiska institutet. Lund, Sweden: Lund Univ. Fact. Humanities \& Theol.; 1995

${ }^{8}$ Hagerman, M. Käraste Herman: rasbiologen Herman Lundborgs gåta. Stockholm, Sweden: Norstedts; 2015.

${ }^{9}$ These are Elsa's words when she recollected her student life to me. Later, my father confirmed that she had told him the same when the persecutions of Jews started in Germany in the 1930s.

${ }^{10}$ Lundborg, H. Svensk raskunskap. Uppsala, Sweden: Almqvist \& Wiksell; 1927.

${ }^{11}$ Her family originated from what is now the corner of Poland, Lithuania, and Kaliningrad. Koritzinsky $\mathrm{H}$. Slektsregister over familiene Lapidus-Nissalowitz-Schwartzman i Norge-Sverige-Danmark. Stockholm, Sweden: privately published; 1946.
} 
methodological approach where, from the onset, practitioners assumed a particular ideological position and then used doubtful methods to prove a theses - as opposed to testing a hypothesis. However, the question remains - how do I, as a practicing scientist, recognize bad science? Can I learn something from the story of Professor Lundborg and Miss Jacobowsky?

\section{From a Culture of Eugenics}

Skull collections were nothing strange in the $19^{\text {th }}$ and early $20^{\text {th }}$ centuries. Indeed, research institutes all over Europe and North America had them. ${ }^{12}$ However suspect these research practices are today, not only scientifically but also socially and politically, craniometry for more than a century was mainstream science, carrying racial biology along with it in its wake. Although scientific developments contributed to the eventual cessation of these practices, it was the atrocities of the Second World War that struck the decisive blow. Yet, these dubious scientific practices and lines of thought, including eugenic legislation, persisted for decades after the War. A potent example being that of Sweden, which continued to allow eugenically motivated sterilizations until the mid-1970s.

Eugenic thought sprung from the same scientific cul-de-sac as racial biology. Indeed, a certain Professor Herman Lundborg also served as Vice President of the International Federation of Eugenics. However, scientists did not promote the eugenic agenda on their own, isolated from the rest of society, and scientists like Lundborg were not mad, nor were they necessarily incompetent it takes more than a cursory dismissal of someone as a racial biologist and eugenicist to show incompetence. Rather, they reflected some of the prevailing ideas of the wider cultural consciousness of the time. The widespread political support for eugenics was an international phenomenon, and the urge to improve the population stock through eugenics came as much from humanists and the clergy, as it did from medical doctors and natural scientists. ${ }^{13}$

There is no doubt in my mind that the natural scientific method, viz. hypothesis-driven observations leading to a new hypotheses, which can be tested, and in time, lead to better hypotheses and theories, is the most powerful methodological approach in discerning a semblance of "The Truth". But I am also fully aware that we will never actually reach "The Truth" - the best we can hope for is to approach it asymptotically. What science does, how it operates, is that it offers the best possible explanations for particular groups of observations - the facts at hand - within the theoretical and mental constraints to which we are all subject. Even if we never reach the so-called "Truth", the approximations already developed using this method have been powerful enough to calculate how to build bridges, spaceships, and atomic force microscopes. I opine, therefore, that the natural scientific method is the most important invention - although gradual - during the past millennium. This is not, of course, to believe that scientific practices have stopped developing. The scientific practices we use today may also, at some point in the future, be regarded with scepticism, just as we ourselves today are sceptic to the practices of racial biology and eugenics. It should be considered that it is difficult to accuse someone for not following good scientific procedures and protocols before those procedures and protocols had been formalized. Criticizing the conclusions drawn from studies undertaken by previous generations of scientists is another matter; that we must do if we

\footnotetext{
12 Alberti, S J M M., Morbid Curiosities. Medical Museums in Nintheenth-Century Britain. Oxford, UK: Oxford University Press; 2011.

${ }^{13}$ Gould, S J., The Mismeasure of Man, $2^{\text {nd }}$ ed. New York, NY: Norton; 1996.
} 
are to learn from the mistakes of our predecessors. We must also ourselves be prepared for critique from our descendants, who will, in turn, also have accumulated more science.

I'm not trying to apologize for bad science, racial biology and eugenics were nothing but Bad Science. Rather, I'm trying to understand why highly intelligent, well trained, so called "world leading" scientists practiced bad science, and in doing so, am seeking to learn from their example and to find ways in which to avoid such mistakes in the future.

At Uppsala, Elsa acquired a Master's degree in geography and biology, and in common with other female students at the time, came to marry one of her professors. Harald was 20 years her senior, and had shortly before their marriage ascended to a chair in botany at Lund University. Elsa gave up her own scientific career when she married, a fate all too common among early female university graduates, but fortunately, she did not have to give up science. Elsa worked as Harald's assistant during all their married life, and eventually edited his magnum opus and was instrumental in its posthumous publication. ${ }^{14}$ Consequently, Elsa and Harald were both well-trained practicing scientists.

Eventually, when my father, too, became Professor in botany at Lund University, we moved into the apartment in which Elsa had lived. She was a hoarder of anything and everything, and the apartment was full with the accumulated books and papers of no less than three generations. Successively, over many years, I cleaned out cupboards and boxes and occasionally happened upon interesting documents.

In my late teens, when I myself first attended university and began my road to becoming a practicing natural scientist, I started to think about the implications of Elsa's story on the practices of natural science. I asked my father how my grandparents had reacted to Lundborg's assignation of Elsa as the "finest example of the pure Nordic race". My father mumbled something about "they probably just laughed at the absurdity". I, however, am not so sure that they did; my grandparents documents and my father's obvious unease discussing the issue indicates otherwise.

Elsa and Harald had political beliefs based on a strong social conscience and were engaged in both the liberal party and the temperance movement. Elsa's family had fled Russian pogroms, and Harald was the son of a smallholder. In the early $20^{\text {th }}$ century society, it was rare for anyone to rise so much "above his station" as Harald had done. From a contemporary perspective, my grandparents may well be expected to repudiate racial biology and eugenics straight off, partly because of the absurdity in assigning a Jewess to the "Nordic Race", but also because these "scientific" practices struck particularly hard at persons of low social standing. Still, I found no documents to this effect. In fact, the reality is quite the contrary! Although Harald, trained not only in botany but also in mathematics, in a letter to his father wrote critically about the bad statistics behind eugenic arguments, he did not, as consequence, draw the conclusion that eugenics had no scientific bearing. This was mildly puzzling, but what really shocked me was finding documents that revealed that Elsa, during the many years she was engaged as a layman judge and social services officer, participated in decisions concerning the sterilization of so-called "inferior individuals"! ${ }^{15}$

\footnotetext{
${ }^{14}$ Kylin, H. Die Gattungen der Rhodophyceen. Lund, Sweden: Gleerups; 1956.

${ }^{15}$ As far as I can glean, she participated in sterilization decisions as late as 1962. Admittedly, however, I do not know how she cast her vote in the committee.
} 
The crux of the matter is, therefore, the following: Did my grandparents, well-trained practitioners of natural science, with strong social consciences and distinctly anti-Nazi views, consider Lundborg's assignation of Elsa as the "finest example of the Nordic Race" as absurd as it actually was? I would hate to think that they did not reflect on this at all, although the only alternative I can surmise is that they accepted the assignation, and believed that Elsa's Nordic ancestors by chance had come to live as converts in a Jewish community in Eastern Europe.

Which of the two aforementioned narratives is the most likely scenario? The bits and pieces of information I have are confusing, based on scanty documents and my grandmother's stories, and so, to this day, I sincerely do not know.

\section{Authority Structures}

How could this ever have come about? Why did my grandparents not take a clear standpoint in the face of obvious absurdity? Part of the answer must relate to the social structures of Sweden and academia during the first half of the $20^{\text {th }}$ century; it was not customary to question someone securely seated on a scientific chair. In a similar vein, a few decades previously, the words of the clergy had been viewed as absolute truth. Although the church successively lost its grip over Swedish society, the authority that the clergy had maintained, during the heyday of Swedish industrialization was, at least in part, afforded to scientists and engineers. Adherence to authority was, therefore, still the normal state of mind - even if authority itself had changed face! To us today, it seems as if it should have been obvious to Elsa how little scientific value there was in racial biology and eugenics. But why, then, did she participate in the sterilization practices that were based on these obviously fallacious lines of thought? I will leave that question open for the reader's consideration.

Although I am convinced that the natural science method is the most powerful invention of the past millennium, I also realize that we, as natural science practitioners, are bound into the social context of our time and by the authority of our peers. We should question, therefore, where in our own scientific practices today, are we as blind to the obvious as Elsa and Harald appear to have been not so long ago? Unless each and every one of us keeps this in mind in the execution of our daily chores, we risk that our science - the science of the present - goes astray, and that we ourselves become practitioners of Bad Science.

\section{The Missing Skull}

There is one remaining line of enquiry to address before I bring this discussion to a close: what then of the "Missing Skull"? When Elsa died in 1968, her body was cremated. As a scientist, and considering the subject of this article, I have to say that I find this most unfortunate! Had that not been the case, Elsa's skull would have made an excellent addition to the ill-famed skull collections of the past. Could there be any better way of humbling contemporary scientific hubris, than to encourage each new generation of natural scientists to reflect upon their daily practices and fallibilities by asking them to stare into the eye sockets of the "scientifically" affirmed so-called "prime example of the Nordic Race", the supposed "Master Race" ... and to contemplate her blood relatives, those that, who amongst thousands of others, died in the gas chambers of Auschwitz? 


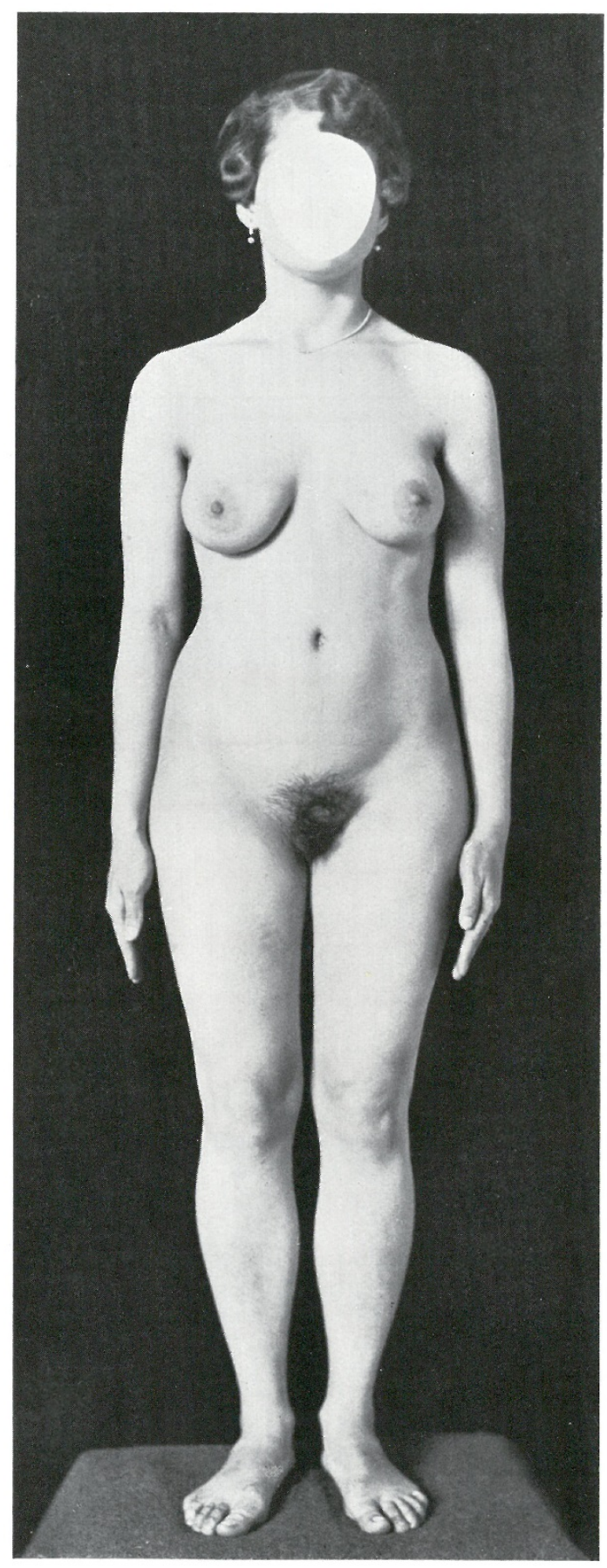

Fig. 1. Rasbiologiska institutets samlingar.

Figure 1. "Granny in the nude"? A plate that, according to the Swedish State Institute for Racial Biology, depicts a typical female representative of the "Nordic Race", possibly the author's grandmother. From Lundborg, H. Svensk raskunskap. Uppsala, Sweden: Almqvist \& Wiksell; 1927. 